\title{
THE VOLUME AND DISTRIBUTION OF BLOOD IN THE HUMAN LEG MEASURED IN VIVO. I. THE EFFECTS OF GRADED EXTERNAL PRESSURE ${ }^{1,2}$
}

\author{
BY JULIUS LITTER AND J. EDWIN WOOD \\ (From the Department of Medicine, Boston University School of Medicine and the Evans \\ Memorial, Massachusetts Memorial Hospitals, Boston, Mass.)
}

(Submitted for publication July 1, 1953; accepted January 27, 1954)

Venous pressure-volume curves obtained by venous congestion may be useful for the study of venous tone in human extremities. However, such pressure-volume curves should be measured from a constant reference point or baseline of venous volume and effective venous pressure.

The purpose of this paper is to show that such a constant baseline is obtained when an external pressure equal to or greater than the natural local venous pressure is applied to the leg. This has been demonstrated by measuring the volume of blood in the human leg, in vivo, at graded external pressures. The data to be presented are not only of physiological interest, but also have a practical bearing on the use of elastic compression to accelerate the linear velocity of blood flow in the leg veins for the prevention of thromboembolic complications in hospitalized patients (1-3).

There have been no quantitative measurements of the volume and distribution of blood in the vessels of the leg, in vivo, with the circulation under normal conditions of rest. Several investigators have reported a few measurements of the blood volume of the leg, using the Evans blue dye (4) or the carbon monoxide (5) method, but their results do not give accurate information about the distribution of blood in the vessels of the leg. Neither method is adaptable for our purpose.

The method employed in the present study is to express the blood from the leg in a water-filled plethysmograph and then to record the increase in leg volume which occurred when the circulation was restored. This was repeated over a wide range of external water pressures applied to the leg. The rationale of the method depends upon the as-

\footnotetext{
1 This work was supported by a grant from the Life Insurance Medical Research Fund.

2 This paper was presented, in part, at a meeting of the New England Cardiovascular Society on February 19, 1951.
}

sumption that the volume of a blood vessel varies directly with the effective intravascular pressure, if other factors are controlled. This assumption has been thoroughly validated by Ryder, Molle, and Ferris using isolated veins (6).

\section{APPARATUS}

The water plethysmograph (Figure 1) described by Wilkins and Eichna (7) was modified at the open ends by replacing the rubber diaphragms (formerly cemented to the skin) with a loose-fitting, thin rubber sleeve (8). The ends of the sleeve were everted and permanently sealed to the flanges at each end of the plethysmograph. The spaces between the leg and the ends of the plethysmograph were closed off by loose-fitting masonite plates which were held firmly against the flange by brass plates (7). When the box was filled with water the hydrostatic pressure forced the loose sleeve in folds against the skin (which had been powdered with talc) and against the inner surfaces of the masonite plates.

A highly satisfactory pressure gasket was made from relatively inelastic, tough neoprene rubber, 1/64 inch thick (Figure 1, Insert). Such a gasket was placed at each end of the leg segment between the thin rubber sleeve and the skin and inner side of the masonite plates. This prevented ballooning of the sleeve between the skin and the inner edge of the masonite plates when high pressures were applied to the water in the plethysmograph. External metal struts (not shown in Figure 1) were attached to the ends of the apparatus so that threaded bolts could be tightened against the outer side of the masonite plates near the free inner edge. This arrangement limited outward movement of the plates under high pressure.

The plethysmograph was connected by rubber tubing to a $100 \mathrm{cc}$. burette, which was supported by clamps so that it could be raised and lowered rapidly. The volume of water in the burette-plethysmograph system (Figure 1) was adjusted by opening stopcock (C) to tube (D) which led to a water reservoir. Water was allowed to run into the reservoir by gravity or was transferred from the reservoir to the burette by a rubber pressure bulb. The burette-plethysmograph system was pressurized through tube (A) connected to the top of the burette by turning a stopcock to a 20-liter air pressure reservoir.

A narrow blood pressure cuff $(\mathrm{H}), 8 \mathrm{~cm}$. wide, was placed on the ankle close to the distal end of the plethys- 


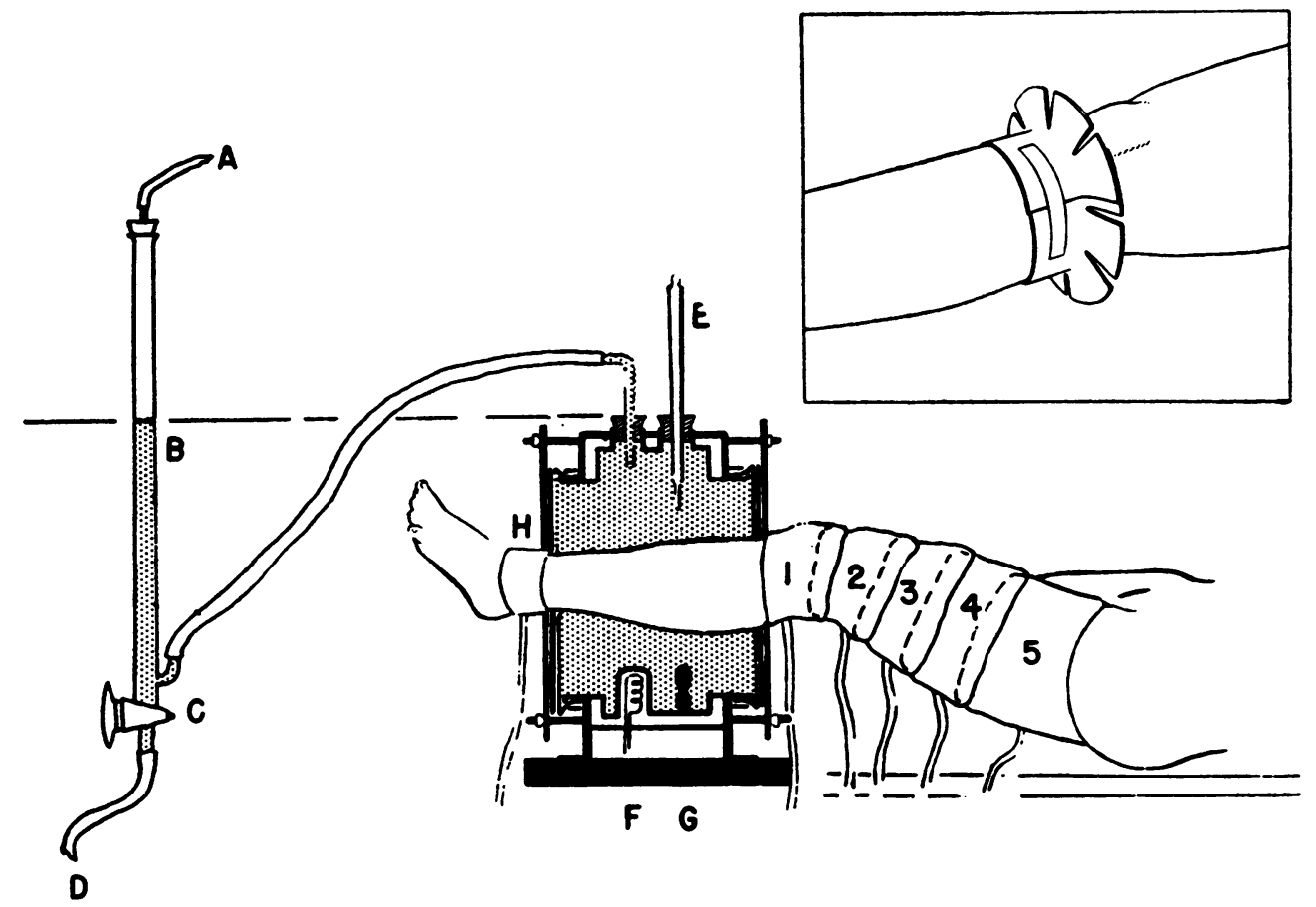

Fig. 1. The Burette-Plethysmograph Apparatus on the Leg of a Supine Subject

" $F$ " is an electric water heater, " $G$ " is a propeller, " $E$ " is a thermometer. The posterior surface of the leg is at heart level. See Text.

Insert: Diagram of neoprene rubber pressure gasket below the knee. The overlapping ends of the loose-fitting gasket are secured with adhesive tape.

mograph. Five cuffs, $14 \mathrm{~cm}$. wide, were placed on the knee and thigh, the lower cuff overlapping the next higher cuff. Two cuffs were used in positions 1, 2, and 5, with the rubber bags on opposite sides of the extremity for more efficient transmission of pressure. All these cuffs were connected through stopcocks to air pressure reservoirs. The thigh cuffs were firmly supported with adhesive tape. Cuffs 1, 2, 3, and 4 were taped to each other to prevent slipping and bulging. This greatly reduced the discomfort at high cuff pressures.

\section{PROCEDURE}

The subjects were healthy young men. One group of experiments was done with the subject supine and the posterior surface of the leg segment in the plethysmograph at heart level, measured $10 \mathrm{~cm}$. anterior to the back. Another group of experiments was done with the upper half of the body uptilted 13 to 18 degrees, and the leg under study slightly lowered, to increase the local venous pressure in the leg. In these experiments heart level was estimated from the phlebostatic level (9). In both groups of experiments a rolled blanket was placed under the thigh and sandbags under the foot so that the extremity was comfortable and relaxed, with the knee only slightly higher than the ankle. The temperature of the water in the burette-plethysmograph and the water reservoir was $32^{\circ} \mathrm{C}$.

The ankle cuff was inflated to a pressure of $260 \mathrm{~mm}$. $\mathrm{Hg}$ to prevent circulation distal to the plethysmograph. One minute later the air pressure in the burette-plethysmograph system was raised to $250 \mathrm{~mm}$. $\mathrm{Hg}$ to express the blood from the leg toward the heart. Water was pumped into the burette from the reservoir as water flowed from the burette into the plethysmograph. This high pressure tended to force the apparatus toward the ankle but such movement was limited by the ankle cuff which exerted counterpressure against the masonite plates. Two minutes later cuff 1 was inflated to $250 \mathrm{~mm}$. $\mathrm{Hg}$ and at 20second intervals cuffs 2 and 3 were similarly inflated. Then the air pressure in the burette plethysmograph system was reduced to atmospheric and cuffs 4 and 5 were inflated at 20 -second intervals to a pressure of $250 \mathrm{~mm}$. Hg. This completed the expression of blood proximally from the leg and thigh. The pressure in cuffs 1, 2, 3, and 4 was then reduced to atmospheric, so that only the highest cuff, 5 , prevented reentry of blood into the extremity.

The external water pressure on the leg was then adjusted at the desired level as measured in the burette in $\mathrm{mm}$. $\mathrm{Hg}$ with reference to heart level. The subject was urged to relax and the pressure was abruptly released from the highest cuff, 5, at zero time. Blood rushed into 
the empty vessels very rapidly due to reactive hyperemia, which gradually subsided until the blood flow had returned to the normal resting level. At first, blood entering the leg displaced water from the plethysmograph into the burette; later, as reactive hyperemia subsided, water flowed back from the burette into the plethysmograph. During this time the burette was rapidly lowered, then raised, so that the water level in it and water pressure on the leg remained constant. It was important that the water pressure on the leg was constant during the observations to prevent errors due to variations in volume of the apparatus with variations of pressure.

Burette readings were taken every 15 seconds for five to eight minutes, until the leg volume did not change significantly for two minutes, indicating that reactive hyperemia was over and the vascular volume had returned to the resting value. The vascular volume of the leg was calculated from the burette readings and the leg volume. The leg volume was calculated from the known capacity of the plethysmograph and the volume of water it contained with the leg segment in it. The initial level of the vater in the burette was a few centimeters above the top of plethysmograph in both groups of experiments. The pro; cedure was repeated numerous times in each experiment on each subject, over a range of external water pressures on the leg up to $60 \mathrm{~mm}$. $\mathrm{Hg}$ above the initial water pressure. The water pressure was usually raised by increments of 5 or $10 \mathrm{~mm}$. $\mathrm{Hg}$.

The assumption that all, or almost all, of the blood in the leg was expressed by an external pressure of $250 \mathrm{~mm}$. $\mathrm{Hg}$ will be considered in the Discussion.
RESULTS

\section{Three experiments on uptilted subjects}

The data obtained in three consecutive experiments on three different subjects studied with the trunk in the $\left(13^{\circ}\right.$ to $\left.18^{\circ}\right)$ uptilted position were similar (Figure 4). Therefore, only one experiment will be discussed in detail and average data will be discussed for the group.

Detailed data. The vascular volume of the leg in subject $\mathrm{D}$. $\mathrm{H}$. from the time blood was allowed to reenter the empty vessels is shown in Figure 2. The number opposite each curve is the external water pressure on the leg in $\mathrm{mm} . \mathrm{Hg}$ (referred to heart level), which ranged from -5 to $+55 \mathrm{~mm}$. $\mathrm{Hg}$. At the lowest external water pressure ( -5 mm. $\mathbf{H g}$ ), the level of the water in the burette was $21.6 \mathrm{~cm}$. (15.9 mm. Hg) above the posterior surfere leg and $6.7 \mathrm{~cm}$. ( $4.9 \mathrm{~mm} . \mathrm{Hg})$ above the anterior surface of the leg. The posterior surface of the leg was $28.4 \mathrm{~cm}$. $(20.8 \mathrm{~mm} \text {. } \mathrm{Hg})^{\prime}$ below heart level

During the first minute after the circulation was restored, the vascular volume reached a peak which varied inversely with the external water pressure. This early peak volume was associated with the rapid blood flow of reactive hyperemia and was

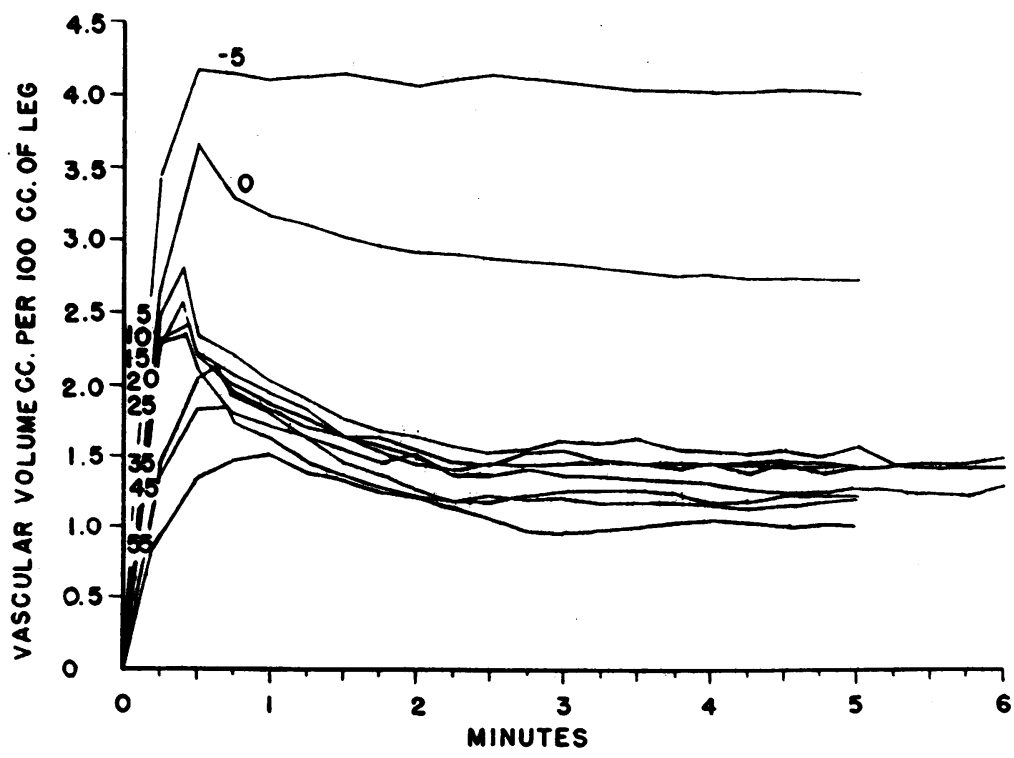

Fig. 2. Time-Vascular Volume Curves in Subject D. H. after Blood Was Allowed to Rz-Enter the Bloodless Extremity

The number opposite each curve is the external water pressure ( $\mathrm{mm}$. $\mathbf{H g}$ ) referred to heart level, applied to the leg during this period. See Text. 
called the peak reactive hyperemia vascular volume, or P.R.H.V.V. Then, at each external water pressure the vascular volume gradually decreased and leveled off as the blood flow subsided to the resting value. The average of the vascular volumes recorded during the last two minutes of each curve when only minor variations in volume occurred was designated the resting vascular volume, R.V.V.

The P.R.H.V.V. and the R.V.V. at each external water pressure for subject $\mathrm{D}$. $\mathrm{H}$. are shown in Figure 3. The effect of increasing the external water pressure on the P.R.H.V.V. was similar to that described by McLennan, McLennan, and Landis, who studied the forearm (10). The interpretation of the factors which determined this curve is complex and not immediately relevant to the present paper. However, we do not subscribe to the explanation which has been suggested (10).

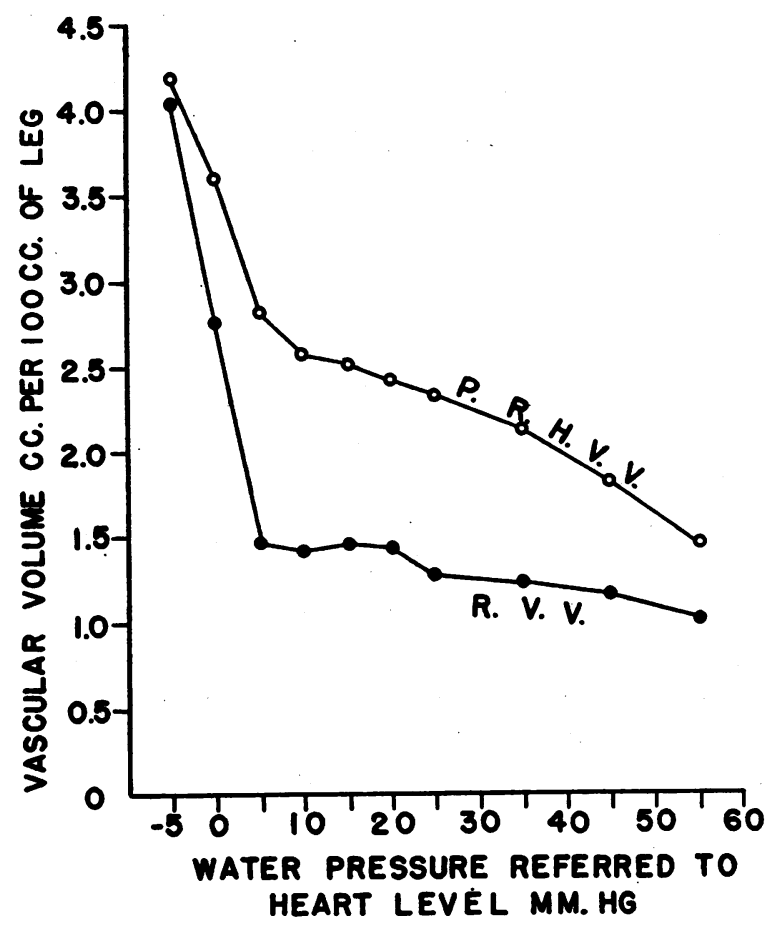

Fig. 3. The Effect of Increasing the External Water Pressure Applied to the Leg on the Peak Reactive Hyperemia Vascular Volume and the Resting Vascular Volume in Subject D. H.

The P. R. H. V. V. occurred during the first minute after blood was allowed to re-enter the extremity (Figure 2) and the R. V. V. was the average of the last two minutes of each curve (Figure 2) when there were only minor variations in vascular volume.

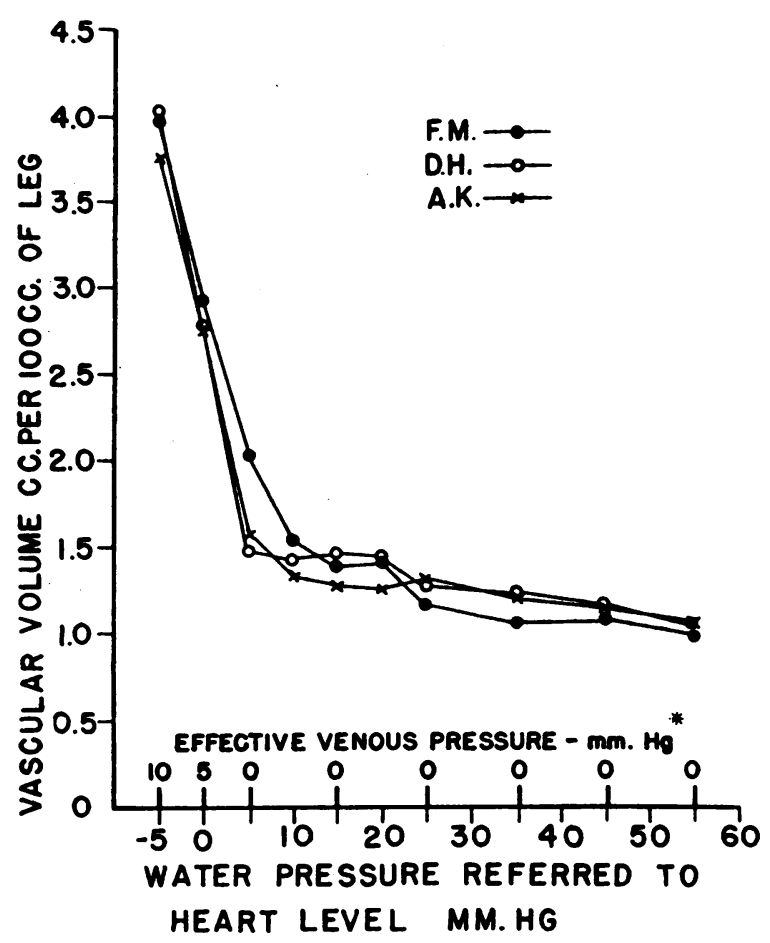

Fig. 4. The Effect of Increasing the External Water Pressure Applied to the Leg on the Resting Vascular Volume of Three Young, Healthy Men, With the Trunk Uptilted 13 to $18^{\circ}$

An increase in water pressure of only $10 \mathrm{~mm}$. $\mathrm{Hg}$ (from -5 to $+5 \mathrm{~mm}$. $\mathrm{Hg}$ ) in two subjects (D. H. and A. K.) and $15 \mathrm{~mm}$. $\mathrm{Hg}$ in the third (F. M.) caused a large decrease in vascular volume.

* See Discussion. The effective venous pressure scale refers to subjects $D$. $H$. and $A$. $K$. only.

The primary concern was to determine the effect of increasing the external water pressure on the resting vascular volume. The vascular volume was $4.0 \mathrm{cc}$. per $100 \mathrm{cc}$. of leg when the external water pressure was $-5 \mathrm{~mm}$. $\mathrm{Hg}$ referred to heart level; it decreased to $2.7 \mathrm{cc}$. when the external water pressure was increased (by $5 \mathrm{~mm}$. $\mathrm{Hg}$ ) to 0 $\mathrm{mm}$. $\mathrm{Hg}$ and to $1.5 \mathrm{cc}$. when the external water pressure was further increased to $+5 \mathrm{~mm}$. $\mathrm{Hg}$. After this, with further increases in external pressure the resting vascular volume abruptly leveled off. Thus, when the external water pressure on the leg was increased by only $10 \mathrm{~mm}$. $\mathrm{Hg}$ (from -5 to $+5 \mathrm{~mm}$. $\mathrm{Hg}$ ), a large decrease in vascular volume occurred, from $4.0 \mathrm{cc}$. to $1.5 \mathrm{cc}$. But, when the external water pressure was increased an additional $50 \mathrm{~mm}$. $\mathrm{Hg}$ (from +5 to $+55 \mathrm{~mm}$. $\mathrm{Hg}$ ), 
there was only a small further decrease in the vascular volume, from $1.5 \mathrm{cc}$. to $1.0 \mathrm{cc}$.

Average data in the three uptilted subjects. The effects of increasing the external water pressure on the resting vascular volume of the leg in three consecutive experiments on three different subjects were very similar (Figure 4 ). The average volume at a water pressure of $-5 \mathrm{~mm}$. $\mathrm{Hg}$ referred to heart level was $3.9 \mathrm{cc}$. An increase in water pressure of only $10 \mathrm{~mm}$. $\mathrm{Hg}$ in two subjects (D. H. and A. K.) and of $15 \mathrm{~mm}$. $\mathrm{Hg}$ in the third (F. M.) reduced the vascular volume in each subject to approximately $1.5 \mathrm{cc}$. The vascular volume decreased only $0.5 \mathrm{cc}$., from 1.5 to $1.0 \mathrm{cc}$, when the external water pressure was further raised to $+55 \mathrm{~mm}$. Hg. Thus, of the total decrease in vascular volume produced by increasing the external water pressure by $60 \mathrm{~mm}$. $\mathrm{Hg}, 82.5$ per cent was due to the first 10 or $15 \mathrm{~mm}$. Hg increase, and only $\mathbf{1 7 . 5}$ per cent was due to the further large increase in pressure.

\section{Four experiments on supine subjects}

A second group of four experiments was done with the subjects supine and with the posterior surface of the horizontal leg segment at approximately heart level (Figure 5). (Two of the four subjects, D. H. and A. K., were also studied in the slightly uptilted position.) The lowest water pressures applied to the leg were 11.5 to $13.2 \mathrm{~mm}$. $\mathrm{Hg}$ above heart level. The initial resting vascular volumes were $1.8 \mathrm{cc}$., $1.7 \mathrm{cc}$., $2.0 \mathrm{cc}$., and $2.3 \mathrm{cc}$. per $100 \mathrm{cc}$. of leg. When the external water pressure was increased the vascular volumes decreased and leveled off at pressures of $20,17.5,16.7$, and $16.5 \mathrm{~mm}$. $\mathrm{Hg}$ corresponding to vascular volumes of $1.2,1.1,1.2$, and $1.3 \mathrm{cc}$. Further increases in the external water pressure to 55 or $65 \mathrm{~mm}$. $\mathrm{Hg}$ caused only minor decreases or variations in vascular volume.

These experiments on supine subjects provide additional evidence that low external water pressures applied to the leg reduce the vascular volume which abruptly levels off and is little affected by further large increases in external pressure. The vascular volumes were more irregular than in the slightly uptilted subjects. It was assumed that this was due to more mechanical movement of the extremity in the supine position.

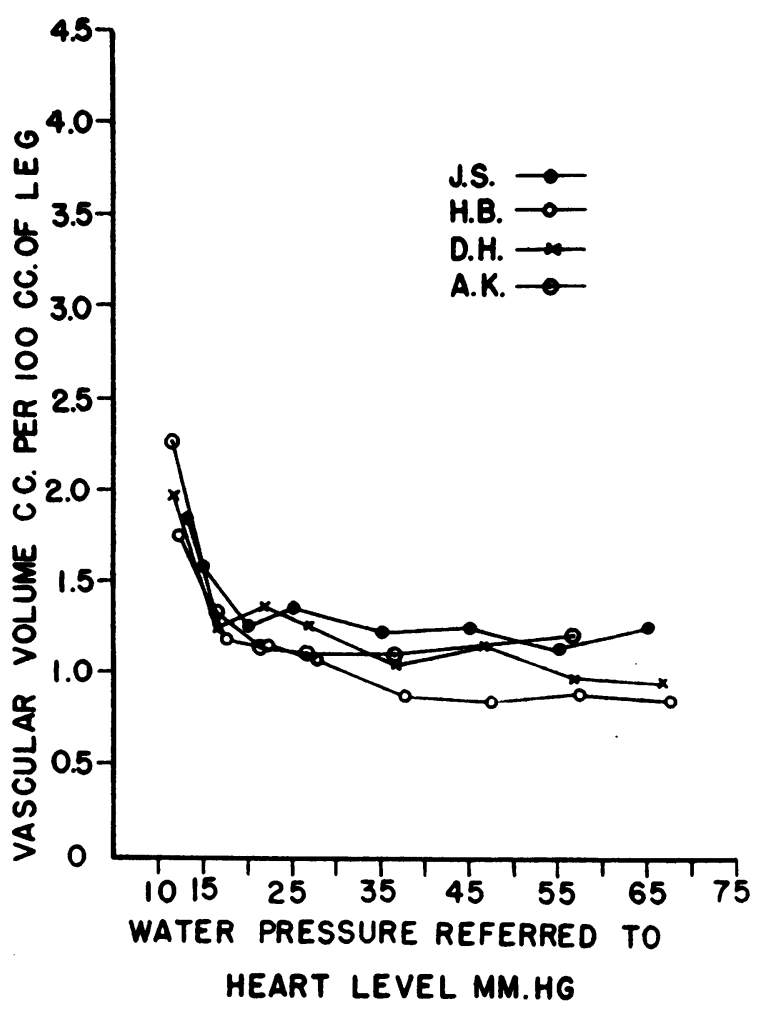

Fig. 5. The Effect of Increasing the External Water Pressure Applied to the Leg on the Resting Vascular Volume of Four Young, Healthy Men, in the Supine $\left(0^{\circ}\right)$ Position

The data obtained in both groups of experiments were consistent and reproducible. In several subjects the vascular volume was redetermined at the lowest external water pressure at the conclusion of the experiment and the values checked very well with the initial observation made several hours earlier. Two subjects, D. H. and A. K., were studied on different days in the supine and slightly uptilted positions. The vascular volume of both subjects at the point where the curves abruptly leveled off was $0.3 \mathrm{cc}$. per $100 \mathrm{cc}$. of leg larger in the uptilted than in the supine position.

\section{DISCUSSION}

\section{Effective venous pressure}

The effective venous pressure is defined as the internal pressure minus the external pressure. The internal pressure which tends to distend a vein is due to the lateral pressure of the blood flowing through it. The lateral pressure is not sig- 
nificantly different from the venous pressure as ordinarily measured and is opposed by the external pressure which tends to collapse the vein. The external pressure is the tissue pressure, usually about $3 \mathrm{~mm}$. $\mathrm{Hg}$ (11). In our experiments the leg was immersed in water and therefore the tissue pressure was increased by the external water pressure. Obviously, an increase in the external water pressure applied to the leg would decrease the effective venous pressure and therefore would decrease the volume of the veins. These considerations apply as well to the venules, capillaries, arterioles, and arteries.

Normally there is a hydrostatic gradient of pressure in the blood vessels of the horizontal leg, when the extremity is at or below heart level. When the leg is immersed in water in a plethysmograph the external pressure of the water on the leg also has a hydrostatic gradient which counterbalances the hydrostatic vascular pressure (if one ignores the slight error due to the greater specific gravity of blood). Therefore, the effective vascular pressures in an immersed limb do not have a hydrostatic gradient and are nearly the same in similar blood vessels (all the veins or all the arteries) whether they are near the anterior or the posterior surface of the leg. Furthermore, the effective vascular pressures in such an immersed limb are not altered by changing the position of the limb (at or below heart level) but are determined by the local venous pressure referred to heart level and the external water pressure referred to heart level.

In the discussion which follows, reference will be made mostly to data obtained in the slightly uptilted subjects. However, the comments apply also to the supine subjects.

\section{The constant baseline of venous volume and effec- tive venous pressure}

The large decrease in vascular volume produced by the first 10 or $15 \mathrm{~mm}$. $\mathrm{Hg}$ increase in external water pressure (Figure 4) must have been due almost entirely to a decrease in the effective pressure and volume of the lowest pressure vessels, the veins (and venules). For, if there had been a significant decrease in the caliber of the capillaries and arterioles there would also have been a significant decrease in the volume flow of blood through the leg segment, since the resistance varies inversely with the fourth power of the diameter of a tube (Poiseuille's law). We have measured the blood flow before, during, and after comparable changes in effective venous pressure produced by such small increases in external water pressure on the leg and observed no significant change (12).

There was abrupt leveling of the vascular volume curves of the leg at an external water pressure of +5 or $10 \mathrm{~mm}$. $\mathrm{Hg}$ above heart level (Figure 4), corresponding to an estimated effective venous pressure near zero. These facts are additional evidence that the preceding large decrease in vascular volume occurred almost entirely in the veins. One can assume that when the water level was raised until the external pressure on the leg became equal to the initial local venous pressure, the effective venous pressure did not become zero, but slightly greater than zero. For at zero the veins at first may have been completely collapsed but, as arterial inflow continued, the pressure in the minute vessels and veins must have risen until the venous pressure was slightly greater than the external pressure (effective venous pressure slightly greater than zero) at which point the veins reopened and venous outflow resumed. This would also occur at all external water pressures greater than the initial local venous pressure, up to diastolic arterial pressure.

Thus, when the external water pressure was equal to or greater than the initial local venous pressure. the effective venous pressure was constant, slightly greater than zero. This is the minimum effective venous pressure possible when the blood is circulating. The venous volume corresponding to this minimum effective venous pressure also must have been constant and is called the "baseline venous volume." These conclusions are consistent with the observations of Ryder, Molle, and Ferris that the volume of an isolated vein in vitro is determined by the effective venous pressure regardless of the absolute value of the external pressure (6). We have obtained experimental evidence in vivo that when the external pressure on the leg is equal to or greater than the local venous pressure the venous volume is virtually constant at the baseline value (11). The venules probably constitute a minor portion of the vascular volume which we have ascribed to the veins (11). 
The importance of the effective venous pressure as the determinant of vascular volume.

It may now be inferred that the average vascular volume of $3.9 \mathrm{cc}$. at an external water pressure of $-5 \mathrm{~mm}$. $\mathrm{Hg}$ referred to heart level was measured at an effective venous pressure of approximately $10 \mathrm{~mm}$. $\mathrm{Hg}$ in two subjects, D. H. and A. K. (Figure 4), and $15 \mathrm{~mm}$. $\mathrm{Hg}$ in the third, F. M. Increasing the water pressure 10 or $15 \mathrm{~mm}$. $\mathrm{Hg}$ reduced the effective venous pressure to slightly greater than zero and caused a large decrease in vascular volume of $2.4 \mathrm{cc}$., from $3.9 \mathrm{cc}$. to $1.5 \mathrm{cc}$., which occurred in the veins. The vascular volume of $1.5 \mathrm{cc}$. included the baseline venous volume and the "normal" volume of the capillaries, arterioles and arteries. The small decrease in vascular volume of only $0.5 \mathrm{cc}$. from $1.5 \mathrm{cc}$. to $1.0 \mathrm{cc}$., produced by raising the external water pressure an additional 45 or $50 \mathrm{~mm}$. $\mathrm{Hg}$, was attributed to decreases in the effective pressures of the capillaries, arterioles and arteries, the effective pressure of the veins remaining slightly greater than zero and the venous volume constant, at the baseline value.

At the highest external water pressure, +55 $\mathrm{mm}$. $\mathrm{Hg}$ referred to heart level, the arteriovenous pressure gradient was considerably decreased. The effective arterial pressure was $60 \mathrm{~mm}$. Hg less than at the start of the experiments and the effective arteriolar and capillary pressures quite low, particularly the latter. The small decrease in vascular volume which occurred, $0.5 \mathrm{cc}$., as a result of the large decreases in effective pressure in the capillaries, arterioles and arteries is further evidence that the combined volume of these vessels is small compared to the veins.

Thus it appears that the volume and distribution of blood in the leg at rest are essentially functions of the effective venous pressure. The vascular volume is always small, $1.5 \mathrm{cc}$. per $100 \mathrm{cc}$. of leg or less, when the effective venous pressure is at the physiological minimum (slightly greater than zero). Large increases in volume occur as a result of modest increases in the effective venous pressure above the minimum value. Although the quantitative relationship between effective venous pressure and venous volume unquestionably varies among the different organs of the body, it is likely that the vascular volume of any organ is a function mainly of the effective venous pressure.

\section{The venous pressure-volume curve}

The concepts elaborated in the foregoing discussion suggest that venous pressure-volume curves measured from the baseline venous volume at an effective venous pressure slightly greater than zero as a point of reference should be physiologically valid. Increases in venous volume produced by venous congestion could then be related to known effective venous pressures. A relatively simple method for determining the venous pressure-volume curve utilizing these principles has been developed and will be presented in another paper (11).

Is all the blood expressed from the leg by an external pressure of $250 \mathrm{~mm} . \mathrm{Hg}$ ?

It is at present impossible to answer this question exactly. However, the main thesis of this paper is valid whether or not all the blood was expressed from the leg, provided that a constant fraction was always removed. The following facts indicate that such was the case. The same vascular volume was obtained in several experiments whether expressing pressures of 200,250 or 300 $\mathrm{mm}$. $\mathrm{Hg}$ had been applied to the plethysmograph. Furthermore, the same vascular volume was obtained repeatedly in the same subject when the same low external pressure was used while blood reentered the limb. Finally, there was good agreement among the data obtained in different subjects.

Other considerations justify the assumption that the fraction of the limb blood volume which may not have been expressed was small.

1. When a lucite (transparent) plethysmograph was filled with water, it could be seen that little if any air was trapped in the irregular, horizontal folds of the loose rubber sleeve which surrounded the leg. This seemed a reasonable analogy with what occurred in the blood vessels.

2. The vascular volume of the leg as determined in our experiments is of the same order as the values obtained by other workers who measured the blood volume by the Evans Blue dye (4) and the carbon monoxide (5) methods. There were great variations among the results obtained by these workers because of the large errors inherent in the methods employed and because the veins in the legs of their subjects were at different and un- 
known effective venous pressures. Ebert and Stead (4) found the average blood volume in one upper and the two lower extremities of five subjects to be $900 \mathrm{cc}$. If one assumes that the average volume of each lower extremity was 13 liters (5) and of one arm 4 liters, then the average blood volume in the extremities of these supine subjects was $3.00 \mathrm{cc}$. per $100 \mathrm{cc}$. of limb. This may be compared with our data by selecting the vascular volume in Figure 4 corresponding to the average effective venous pressure in the leg of a supine subject. The average venous pressure in the leg of a supine person referred to heart level (about $10 \mathrm{~cm}$. anterior to the bed) is $13 \mathrm{~cm} . \mathrm{H}_{2} \mathrm{O}$ (13). Since the average male leg is about $13.5 \mathrm{~cm}$. thick the bulk of the leg is below heart level and the average local venous pressure would be somewhat higher, about $15 \mathrm{~cm} . \mathrm{H}_{2} \mathrm{O}$ or $11 \mathrm{~mm}$. $\mathrm{Hg}$. Subtracting $3 \mathrm{~mm}$. $\mathrm{Hg}$ for the average tissue pressure in the leg (11), the average effective venous pressure would be $8 \mathrm{~mm}$. $\mathrm{Hg}$. Accordingly, the vascular volume of the leg of a supine subject without a plethysmograph on the extremity would be approximately $3.5 \mathrm{cc}$. per $100 \mathrm{cc}$. of leg (Figure 4). This compares favorably with the value of $3.00 \mathrm{cc}$. derived above.

In summary, it appears that almost all, if not all, the blood was expressed from the leg in our experiments when the pressure in the plethysmograph was raised to $250 \mathrm{~mm}$. $\mathrm{Hg}$. In any case, the fraction of the blood volume which may have remained in the leg was constant and relatively small.

\section{The efficient transmission of external water pres- sure to the leg}

If low external water pressures were not efficiently transmitted to almost the entire leg segment in the plethysmograph one would expect that falsely high values for vascular volume might be obtained due to the accumulation of blood in places where the effective vascular pressures were little affected by the low external pressure, namely at the thick proximal end of the leg segment (14). If this were true, then when the external water pressure was raised 5 or $10 \mathrm{~mm}$. $\mathrm{Hg}$ the transmission of this pressure to the proximal part of the leg might become much more efficient, resulting in marked decreases in vascular volume such as those observed.
However, comparison of the experiments done in the uptilted and supine subjects indicates that if such an artefact existed it was not important. The lowest water pressure used, when referred to the surface of the leg, was practically the same in both groups of experiments, but the average vascular volumes were distinctly different: $3.9 \mathrm{cc}$. for the uptilted (Figure 4) and $1.9 \mathrm{cc}$. for the supine (Figure 5) subjects. The larger vascular volume in the uptilted subjects was due to the higher effective venous pressure in the leg in this position resulting from the fact that the leg was below heart level, whereas the legs of the supine subjects were at heart level. Furthermore, it required only about $5 \mathrm{~mm}$. $\mathrm{Hg}$ additional water pressure in the supine subjects to reduce the effective venous pressure to slightly greater than zero after which the vascular volume remained almost constant, whereas in the uptilted subjects it required 10 or $15 \mathrm{~mm}$. $\mathrm{Hg}$ additional water pressure to achieve the same result. Since the vascular volume in each case was dependent on the effective venous pressure rather than on the absolute value of the external water pressure referred to the surface of the leg, one must conclude that the water pressure was efficiently transmitted.

\section{The effect of external pressure on the interstitial fluid volume}

Landis and Gibbon showed that when a pressure of $200 \mathrm{~mm}$. $\mathrm{Hg}$ was applied to the forearm for two minutes the volume of interstitial fluid expressed was insignificant (15). This probably also applies to the leg at a pressure of $250 \mathrm{~mm}$. $\mathrm{Hg}$ for two minutes. The resting vascular volume was measured at external water pressures up to $60 \mathrm{~mm}$. $\mathrm{Hg}$ five to eight minutes after blood flow resumed. During this period no more, and probably less, interstitial fluid could have reaccumulated than was expressed by the high pressure of $250 \mathrm{~mm}$. $\mathrm{Hg}$. Therefore, the values obtained for the resting vascular volume measured at external pressures up to $60 \mathrm{~mm}$. $\mathrm{Hg}$ included only insignificant amounts of interstitial fluid.

\section{SUM MARY AND CONCLUSIONS}

The leg was rendered as bloodless as possible by pressurizing it in a water-filled plethysmograph at a suprasystolic pressure. Blood was prevented from reentering the leg by a cuff at suprasystolic 
pressure proximal to the plethysmograph while the water pressure in the plethysmograph was readjusted to an exact (low) level. The circulation was then restored and the volume of blood that entered the leg at this external pressure was measured after reactive hyperemia had subsided. Such measurements were repeated over a wide range of external water pressures.

Small increases in external water pressure produced large decreases in the resting vascular volume which leveled off abruptly when the external pressure had risen to equal the venous (or venular) pressure. At that point the effective venous pressure was reduced to slightly greater than zero and the venous volume was at the "baseline value." The large decrease in vascular volume was attributed to the reduction in the effective venous (and venular) pressure. Further large increases in the external water pressure caused only small decreases in the vascular volume, attributed to reductions in the effective pressures of the capillaries, arterioles, and arteries.

It was concluded that :

1. A constant baseline of venous volume at an effective pressure slightly greater than zero is obtained when an external pressure equal to or greater than the natural local venous pressure is applied to the leg.

2. Changes in vascular volume produced by changes in external pressure are due almost entirely to changes in effective venous (and venular) pressure.

3. The combined volume of the capillaries, arterioles, and arteries is small regardless of the effective pressures in these vessels.

4. The volume and distribution of blood in the leg at rest are essentially functions of the effective venous pressure.

\section{ACKNOWLEDGMENT}

The authors wish to thank Dr. Robert W. Wilkins for his constant encouragement and helpful criticisms.

\section{REFERENCES}

1. Wilkins, R. W., Mixter, G., Jr., Stanton, J. R., and Litter, J., Elastic stockings in the prevention of pulmonary embolism: a preliminary report. New England J. Med., 1952, 246, 360.

2. Wilkins, R. W., and Stanton, J. R., Elastic stockings in the prevention of pulmonary embolism. II. A progress report. New England J. Med., 1953, 248, 1087.

3. Litter, J., Thromboembolism: its prophylaxis and medical treatment. Recent advances. Med. Clin. North America, Sept., Boston number, 1952, 36, 1309.

4. Ebert, R. V., and Stead, E. A., Jr., The effect of the application of tourniquets on the hemodynamics of the circulation. J. Clin. Invest., 1940, 19, 561.

5. Asmussen, E., The distribution of the blood between the lower extremities and the rest of the body. Acta physiol. Scandinav., 1943, 5, 31.

6. Ryder, H. W., Molle, W. E., and Ferris, E. B., Jr., The influence of the collapsibility of veins on venous pressure, including a new procedure for measuring tissue pressure. J. Clin. Invest., 1944, 23, 333.

7. Wilkins, R. W., and Eichna, L. W., Blood flow to the forearm and calf. I. Vasomotor reactions: role of the sympathetic nervous system. Bull. Johns Hopkins Hosp., 1941, 68, 425.

8. Wise, C. S., Fluid displacement and pressure plethysmography in Methods in Medical Research, 1948, 1, 189.

9. Winsor, T., and Burch, G. E., Phlebostatic axis and phlebostatic level, reference levels for venous pressure measurements in man. Proc. Soc. Exper. Biol. \& Med., 1945, 58, 165.

10. McLennan, C. E., McLennan, M. T., and Landis, E. M. The effect of external pressure on the vascular volume of the forearm and its relation to capillary blood pressure and venous pressure. J. Clin. Invest., 1942, $21,319$.

11. Litter, J., Wood, J. E., and Wilkins, R. W., The venous pressure-volume curve of the human leg measured in vivo. In preparation.

12. Litter, J., Unpublished observations.

13. Winsor, T., and Burch, G. E., Use of the phlebomanometer: Normal venous pressure values and a study of certain clinical aspects of venous hypertension in man. Am. Heart J., 1946, 31, 387.

14. Landowne, M., and Katz, L. N., A critique of the plethysmographic method of measuring blood flow in the extremities of man. Am. Heart J., 1942, 23, 644.

15. Landis, E. M., and Gibbon, J. H., Jr., The effects of temperature and of tissue pressure on the movement of fluid through the human capillary wall. J. Clin. Invest., 1933, 12, 105. 